\title{
O ENSINO DA LINGUAGEM AUDIOVISUAL E IMAGENS-SINTOMAS
}

\author{
Arthur Medrado $^{{ }^{*} *}$ \& Margareth Diniz ${ }^{2}$
}

\section{RESUMO}

MEDRADO, A.; DINIZ, M. O Ensino da Linguagem Audiovisual e Imagens-Sintomas . Perspectivas Online: Humanas \& Sociais Aplicadas, v.10, n.28, p.98 -1132020.

Nesse artigo abordaremos um processo de produção teórico/prático que pretendeu a elaboração de uma metodologia de intervenção, a Olhares (Im)possíveis, por meio de oficinas com a linguagem audiovisual. Estes escritos lançam um olhar sobre o trabalho desenvolvido com crianças de 10 e 11 anos, da escola Municipal Professor Adhalmir Santos Maia, na periferia de Ouro Preto durante os meses de maio e dezembro de 2017. Neste artigo iremos, em um primeiro momento, lançar os olhares para uma imagenssintoma produzida durante uma das atividades. A partir de sua dimensão acidental, inspirando-nos no paradigma indiciário de Carlo Guinzburg (1989), encontraremos nas perspectiva do detalhe apresentada por Rancière (2009), uma possibilidade de análise. Em seguida, iremos nos atentar a perceber como essa imagem parece funcionar como uma imagem-intolerável (Rancière, 2012). Por último, a partir da noção de violência (Soares, 2011 e Clastres, 2004) iremos entender que o trabalho com essas imagens-intoleráveis (a elaboração de seus testemunhos) permitiu aos sujeitos a criação de pequenos espaços de fuga as realidades as quais estão inseridos/as.

Palavras-chave: Educação; Pesquisa intervenção; Audiovisual; Psicanálise; Criança. 


\title{
THE TEACHING OF AUDIOVISUAL LANGUAGE AND SYMPTOM- IMAGES
}

\begin{abstract}
In this article, we will approach a theoretical / practical production process that intended the development of an intervention methodology, the "Looks (Im) Possible"), through workshops with the audiovisual language. These writings take a look at the work developed with children aged 10 and 11, from the Municipal School Professor Adhalmir Santos Maia, on the outskirts of Ouro Preto during the months of May and December 2017. In this article we will, in a first moment, launch looks at an image produced during one of the activities. From its accidental dimension,

inspiring us in the indicative paradigm of Carlo Guinzburg (1989), we will find in the perspective of the "detail" presented by Rancière (2009), a possibility to analyze it. Then, we will look at how this image seems to function as an "intolerable image" (Rancière, 2012). Finally, from the notion of violence (Soares, 2011 and Clastres, 2004) we will understand that working with these "intolerable images" (the elaboration of their testimonies) allowed the subjects to create small spaces of escape from the realities which are inserted.
\end{abstract}

Keywords: Education. Research intervention. Audio-visual. Psychoanalysis. Child.

\footnotetext{
${ }^{1}$ Universidade Federal Fluminense (UFF) - Rua Alexandre Moura, 8. Bloco A, sala 202. São Domingos, Niterói, RJ, CEP: 24210-200, Brasil.

${ }^{2}$ Instituto de Ciências Humanas e Sociais da Universidade Federal de Ouro Preto (UFOP) - Rua do Seminário, s/n, Mariana, MG, CEP: 3520000, Brasil.

(*) e-mail: contato@olharesimpossiveis.com.br

Data de recebimento: 30/04/2020. Aceito para publicação: 15/06/2020 . Data da publicação: 23/06/2020.
}

Persp. Online: hum \& sociais aplicada., Campos dos Goytacazes, 28 (10)98-113- 2020 seer.perspectivasonline.com.br 


\section{INTRODUÇÃO}

Ouro Preto é uma cidade mineira que já foi conhecida como Vila Rica (até 1823). Devido a sua altíssima importância econômica, graças presença de minerais, foi capital do Estado nos séculos XVII e XVIII. Vila Rica, por conta da extração aurífera, manteve a economia brasileira por quase um século. A cidade passou por um período de decadência e abandono, contudo seu patrimônio material foi conservado, fator que levou a cidade a ser declarada Monumento Nacional em 1933, e ter todo seu centro histórico tombado pelo Instituto do Patrimônio Histórico Artístico Nacional (IPHAN) em 1938. Em 1980 Ouro Preto se tornou o primeiro bem cultural brasileiro inscrito na Lista do Patrimônio Mundial.

Desde então, a cidade se mantém principalmente da mineração e do turismo. Seus monumentos são visitados por pessoas de todo o mundo. Porém, o que parece não ficar evidente para a maior parte das pessoas que visitam a cidade (e também para a maioria dos estudantes universitários, e trabalhadores e trabalhadoras da mineração, que ali residem temporariamente) é que para além do centro histórico, Ouro Preto tem diversas periferias, tanto no sentidos espacial (a distância do centro), como no sentido econômico.

Em 2017, iniciamos uma série de atividades com a linguagem audiovisual em escolas públicas: a Olhares (Im)Possíveis. O principal objetivo do trabalho desenvolvido foi o de exercitar o olhar de quem participa, escutando sobre suas histórias de vida por meio de encontros presenciais, no que diz respeito às experiências e relações afetivas dentro dos espaços da cidade, utilizando como dispositivo principal a produção audiovisual. O grupo que recebeu as oficinas em 2017 era composto por 10 crianças de 10 e 11 anos, do Ensino fundamental I na escola Municipal Professor Adhalmir Santos Maia, situada no bairro Nossa Senhora do Carmo, o Pocinho, na periferia da cidade.

O trabalho apostou na experimentação do vídeo como proposta de dispositivo processual onde a escuta de estudantes garantia a possibilidade de apostar nos processos de realização audiovisual e nos afastar da ideia de produto. Ou seja: um trabalho com o vídeo/cinema onde o foco não era a produção de um filme (ainda que eles acontecessem), mas seus processos em relação com as possibilidades de uma prática estético-política que hoje também podemos entender como práticas clínicas. Durante as oficinas o audiovisual funcionou como dispositivo para o encontro, para a partilha, mas também pré-texto para as conversações com os/as estudantes. Nesse sentido, a ideia de dispositivo (MIGLIORIN, $2014 ; 2015)$, como aquilo que coloca em crise a articulação entre um comando fechado e ao mesmo tempo aberto à inventividade, foi apropriada na articulação de três momentos que garantem a emergência das imagens-sintomas produzidas pelas crianças envolvidas.

As imagens-sintomas surgem como o registro que foge ao controle de quem as realiza. Isso se dá a partir da interrupção de um fluxo normal das coisas. Ou seja: "O que a imagem-sintoma interrompe não é outra coisa senão o curso normal da representação. (...) um sintoma jamais emerge em um momento correto, aparece sempre a contrapelo, como uma velha enfermidade que volta a importunar nosso presente" (DIDI-HUBERMAN, 2005, p. 44).

Neste artigo iremos, em um primeiro momento, lançar os olhares para uma imagem produzida durante uma das atividades. A partir de sua dimensão acidental, inspirando-nos no paradigma indiciário de Carlo Guinzburg (1989), encontraremos nas perspectiva do detalhe apresentada por Rancière (2009), uma possibilidade para analisá-la. Em seguida, iremos nos atentar a perceber como essa imagem parece funcionar como uma imagem-

Persp. Online: hum \& sociais aplicada., Campos dos Goytacazes, 28 (10)98-113- 2020

seer.perspectivasonline.com.br 
intolerável (RANCIÈRE, 2012). Por último, a partir da noção de violência (SOARES, 2011; CLASTRES, 2004) iremos entender que o trabalho com essas imagens-intoleráveis (a elaboração de seus testemunhos) permitiu aos sujeitos a criação de pequenos espaços de fuga as realidades as quais estão inseridos/as. Uma ampliação do olhar que garantia a invenção de mundo.

A seguir, vamos apresentar a metodologia utilizada durante essa pesquisa.

\section{METODOLOGIA}

Como dito, Olhares (Im)possíveis foi um trabalho de produção teórico/prático que pretendeu a elaboração de uma metodologia de intervenção, por meio de oficinas de linguagem audiovisual realizadas com grupos, dentro do Programa de Educação Patrimonial Sentidos Urbanos em parceria com o coletivo MICA Mídia, identidade, cultura e Arte.

O trabalho de implementação dessa metodologia aconteceu entre os meses de maio e dezembro de 2017, realizando-se assim mais de 20 encontros tanto na escola, como em outros espaços da cidade. As 10 crianças envolvidas nessa etapa da metodologia pertenciam a um contexto de alta vulnerabilidade social e a escola em que atuamos, até aquele momento, praticamente não contava com nenhum projeto cultural e social. Nessa etapa atuamos com uma turma do $5^{\circ}$ Ano - Ensino Fundamental I.

Desde então, além da escola analisada o trabalho contemplou também outros 20 grupos (que incluíram escolas, núcleos de arte, festivais e simpósios) em cinco cidades mineiras alcançando públicos variados. Esses trabalhos também nos auxiliam a pensar uma série de possibilidades para a oficina, porém nos atentarmos a pensar, nesse caso, as possibilidades com um público específico: as crianças. É importante dizer que desde 2019 formamos um coletivo de cinema em uma Escola Estadual em Ouro Preto.

No ano de 2017, para a implementação da propostas, partimos da noção de dispositivo, desenvolvida por Cezar Migliorin no trabalho com o projeto Inventar com a Diferença - Cinema e Direitos Humanos. Com esse autor entenderemos como dispositivo aquilo que coloca em crise o participante durante articulação entre um comando fechado e ao mesmo tempo aberto à inventividade. A partir dessa noção apropriada, articulou-se para a primeira etapa da metodologia de intervenção três momentos. São eles: 1) Cartão Postal, 2) Minuto Lumière e 3) Filme-Carta.

O dispositivo Cartão Postal foi elaborado de acordo com o contexto da cidade de Ouro Preto para um trabalho a partir da construção de mapas afetivos, onde as crianças deveriam selecionar e identificar pontos do trajeto cotidiano que lhes chamavam atenção. Lugares, situações, encontros, cheiros, lembranças, enfim: tudo o que salta aos olhos nos caminhos que realizam. Desses registros iniciais (que aconteciam por meio da escrita, desenho, tópicos) elas selecionaram um ponto e/ou situação para que, por meio de fotografia, pudessem se tornar seus próprios Cartões Postais.

Sobre caminhar pela cidade: "O caminhar pela cidade assemelha-se a navegar por um hipertexto, que permite diversas associações significantes, promovendo uma leitura multilinear, pautada no percurso e não mais no plano representativo." (Silveira, 2020, p.3).

Persp. Online: hum \& sociais aplicada., Campos dos Goytacazes, 28 (10)98-113- 2020 
Observamos que a experiência com metodologia da cartografia garantiu a observação de que as histórias contadas a partir dos mapas levavam às experiências traumáticas das crianças, como por exemplo as relações conflituosas com a polícia e também com as dinâmicas do tráfico de drogas presentes no bairro, o medo das autoridades e agressões sofridas dentro e fora do ambiente familiar. Salta aos olhos que nenhuma dessas situações tenha sido escolhida pelas crianças durante os momentos de registro fotográfico. Percebemos, então, que o medo impedia a denúncia. Porém a metodologia utilizada, apostando na produção de imagens, permitia com que a palavra circulasse e os testemunhos inevitavelmente, aparecessem. Essa metodologia garantia a emergência das imagenssintomas do cotidiano das crianças que participaram da pesquisa.

Algo semelhante também aconteceu durante a última atividade realizada na primeira fase do trabalho, quando novamente apostamos na cartografia como processo metodológico inicial. Nesse caso, as crianças trabalharam sobre um mapa coletivo onde deveriam identificar e apresentar os sonhos e desejos para a escola, o bairro, a cidade e também para si mesmos. Na cartografia dos sonhos as crianças apresentaram então os desejos de justiça, como principal temática subjetiva, mas a grande maioria dos sonhos estava acoplada a ideias altamente burguesas e capitalistas: a mansão, o carro importado, a abundância de dinheiro, as roupas da moda e o ideal familiar heteronormativo foram reproduzidos nas colagens que deram origem à intervenção com a técnica lambe-lambe realizada em um dos muros da escola.

Entendemos esse trabalho teórico prático, com encontros presenciais e escrita sobre o processo a posteriori como uma pesquisa- intervenção:

(...) diferenciando-a das outras formas de pesquisa participativa, é importante ressaltar que essa prática de pesquisa se consolida como uma tendência entre as pesquisas participativas, as quais têm como objetivo observar e investigar (através da intervenção) a vida dos sujeitos envolvidos ("coletividades") em sua diversidade qualitativa, assumindo a postura de uma intervenção com caráter socioanalítico. (MEDRADO; DINIZ, 2020, p. 115-116).

A pesquisa intervenção realizada foi construída levando em consideração o paradigma indiciário de Ginzburg. Essa aposta metodológica entende o caráter artesanal da feitura da pesquisa e garante que os pesquisadores e pesquisadoras possam operar com o que parece não ter importância, ou simplesmente as coisas que aparentemente poderiam escapar há um olhar objetivo sobre todo o processo. Sobre o paradigma indiciário:

O paradigma indiciário é um procedimento ou princípio construtivo desenvolvido pelo historiador italiano Carlo Ginzburg. Constitui-se pelos achados que estão presentes nas imagens de investigacões científicas inteiramente diversas. Ginzburg define que esses achados "são frutos do acaso e não de curiosidade deliberada. Surge em algum momento da pesquisa onde a sensacão de ter encontrado uma pista relevante e ao mesmo tempo a consciência aguda da ignorância sobre o que aquilo significa" (GINZBURG, 1989 apud RODRIGUES, 2005 p. 213). Ginzburg se propõe a tratar o paradigma indiciário tendo como cenário o campo de pesquisa na área da História, especificamente pensando a história da arte e o gênero ensaístico como forma de apresentacão dos dados no texto. Suas reflexões também podem servir para pensar o modo de pesquisar em outras áreas e campos, bem como outros tipos de texto. (MEDRADO; DINIZ, 2020, p. 109).

Persp. Online: hum \& sociais aplicada., Campos dos Goytacazes, 28 (10)98-113- 2020 
Operar com esse paradigma é o que permite nos atentar aos detalhes, mas também aos acidentes que, no caso da pesquisa com sujeitos e produção de imagens, garante que em alguns momentos as imagens produzidas possam emergir como imagens-sintoma.

\section{RESULTADOS E DISCUSSÃO}

\section{O DETALHE NO MINUTO LUMIÉRE "JUNIOR GAMER": ACIDENTE CRIADOR DE IMAGENS-SINTOMAS}

Gostaríamos de analisar um dos resultados do dispositivo Minuto Lumière, que consiste em realizar um plano até um minuto com a câmera fixa em um tripé. Essa prposta nós permite apresentar o conceito de plano no cinema: tudo que acontece entre o momento que colocamos a câmera para gravar $(r e c)$ até finalizar essa gravação. O plano é a unidade mínima da linguagem cinematográfica.Nesse caso, nos impressiona como a diferença entre a proposta inicial do estudante ("filmar todos brincando no parquinho") faz transparecer um dinâmica frequente nas primeiras atividades: a exclusão das meninas do grupo.

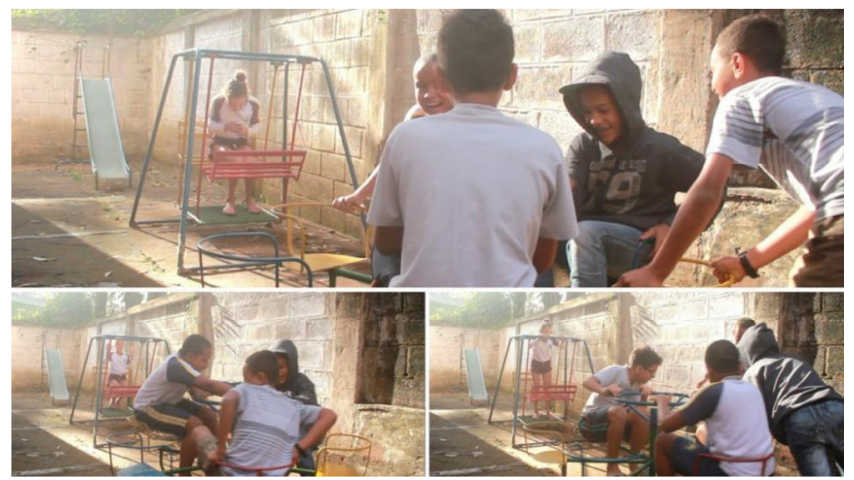

Figura 1: Colagem de frames do Minuto Lumière "Junior Gamer". Fonte: Pesquisa, 2017.

Para realizar esse dispositivo é necessário escolher alguma situação que contenha movimento para ser gravada por 1 minuto com a câmera fixa em um tripé. Nesse dia, todas as crianças presentes captaram 1 minuto, nomearam seus vídeos e os assistimos todos/as juntos/as.

Um deles nos chamou atenção, por algo que acontece no cotidiano se transbordar no interior da composição dessa imagem: a exclusão das meninas do grupo.

Para analisar esse plano iremos, com Rancière (2009), nos atentar aos detalhes. Para esse autor, tal tarefa apresenta duas vertentes: a dos sinais e a dos acidentes. Ambas foram apresentadas no método Morelli (GINZBURG, 1989), e levada a cabo por Huberman (2013), quando se apresenta a perspectiva do detalhe na pintura, que aqui se aplicará ao vídeo. Para Rancière o detalhe funciona como objeto parcial, fragmento inacomodável que desfaz a ordenação da representação para dar lugar à verdade inconsciente que não é de uma história individual, mas que é oposição de uma ordem a outra: o figural sob o figurativo, ou o visual sob o visível representado (RANCIÈRE, 2009, p. 59).

É o que vemos no Minuto Lumière apresentado na figura 1. O detalhe do segundo plano da menina isolada denuncia a existência das práticas opressoras de silenciamento e violência em relação à mulher na sociedade, por consequência, na escola. Quando um dos

Persp. Online: hum \& sociais aplicada., Campos dos Goytacazes, 28 (10)98-113- 2020 seer.perspectivasonline.com.br 
estudantes resolve filmar "todos brincando no parquinho" e o que temos como resultado são "todos os meninos brincando no parquinho juntos, sem a menina", temos uma imagem contraditória: "É talvez quando as imagens são mais intensamente contraditórias que elas são mais autenticamente sintomáticas" (DIDI-HUBERMAN, 2013, p. 336).

Do mesmo modo, a imagem do Minuto Lumière apresentada pode ser pensada como um acidente, visto que o seu resultado nos apresenta algo não esperado (pela criança, menino, que o realizou) para essa análise. Sobre o acidente, Didi-Huberman nos diz, ancorado na análise freudiana de histeria, que

o acidente - gesto insensato, informal, incompreensível, "não icônico" - era claramente soberano: e não apenas de uma soberania sintagmática, se podemos dizer, ou seja, que num tal momento o acidente domina tudo e tiraniza o corpo inteiro; mas também de uma soberania "paradigmática", ou seja, que tal momento libera uma significância, envolve um destino, um fantasma originário, portanto faz trabalhar uma estrutura (HUBERMAN, 2013, p. 333-334).

O vídeo realizado é mais um testemunho dos contextos sociais e escolares nos quais estão inseridas essas crianças. É uma imagem-sintoma, mais uma, que a experiência com a realização audiovisual faz emergir. Deve-se considerar que o sintoma é:

\begin{abstract}
um acontecimento crítico, uma singularidade, uma intrusão, mas também é instauração de uma estrutura significante, de um sistema que o acontecimento tem por tarefa fazer surgir, mas parcialmente, contraditoriamente, de modo que o sentido advenha apenas como enigma ou fenômeno-índice, não um conjunto estável de significações (HUBERMAN, 2013, p. 344).
\end{abstract}

Eis o destino da estética do sintoma, "uma estética dos acidentes soberanos" (Huberman, 2013, p. 337). Tais perspectivas nos leva a pensar que o trabalho com a ideia de dispositivo garante o surgimento dessas imagens justamente com a introdução e criação de um Mafuá. Com Cezar Migliorin entenderemos o Mafuá é uma desordem com ordem momentânea, que se modifica a partir da chegada de cada elemento, que pode ser uma pessoa, um dispositivo fotográfico, ou uma lente. Percebemos que essa imagem também pode ter: um valor de estilhaço, uma crise que faz emergir (e lampejar) imagens-sintoma dos contextos onde a prática foi realizada. Imagens que produzem dupla distância. Antes de falar dessa dupla distância vale explicitar melhor o conceito de mafuá:

O Mafuá é a própria operação do pensamento; não um lugar, mas o que se constitui nas aparições quando algo é pensado, quando uma ordem qualquer se estabelece, quando uma forma se materializa. [...] o mafuá é um enroscado com pontos de convergência e ordens circunstanciais, sem divisões e partilhas préestabelecidas; e, se tudo correr bem, com algo de carnavalesco e festivo (MIGLIORIN, 2015, p. 161).

Para falar das duplas distâncias é necessário retomar o conceito benjaminiano de aura. Uma leitura pessimista de Walter Benjamin afirma que a era da reprodutibilidade técnica haveria eliminado a existência da aura. Esse conceito, o de aura, diz sobre "uma trama singular de espaço tempo" (Benjamin apud Didi-Huberman, 2010, p. 147), e está atrelado à crise do fim da experiência apresentado na modernidade. E, nesse sentido, é necessário superar esse dilema através de uma perspectiva que ultrapasse e se posicione para além dele mesmo (o dilema). Vale trazer aqui "o acontecer" da aura entre o que vemos e o que nos olha, de modo que seria o "espaçamento tramado do olhante e do olhado, do olhante pelo olhado. Um paradigma visual que Benjamin apresentava antes de tudo como um poder da distância:

Persp. Online: hum \& sociais aplicada., Campos dos Goytacazes, 28 (10)98-113- 2020 
Única aparição de uma coisa longínqua, por mais próxima que possa estar [...] o objeto aurático supõe assim uma forma de varredura ou de ir e vir incessante, uma forma de heurística na qual as distâncias - as distâncias contraditórias - se experimentariam umas às outras, dialeticamente (BENJAMIN apud DIDIHUBERMAN, 2010, p. 147-148).

Para Didi-Huberman, esse entrelaçamento da onipotência do olhar e de uma memória, que se acessa como quando estamos perdidos em uma "floresta de símbolos", é um choque, um conflito, uma força do desejo. Nessa trama,

o passado se dialetiza na protensão de um futuro, e dessa dialética, desse conflito, justamente surge o presente emergente - e anacrônico - da experiência aurática, esse "choque" da memória involuntária que Benjamin propõe seja visto em geral, e em toda a extensão problemática da palavra, segundo seu valor de sintoma: "Esse processo, diz ele ao falar da aura, tem valor de sintoma; sua significação ultrapassa o domínio da arte (DIDI-HUBERMAN, 2010, p.151).

Por isso, é importante entender a aura como uma instância dialética, cuja estrutura ela mesma tenta pensar. E se afastar também dessa visão histórica e antropologicamente enraizada sobre a arte e seu valor de culto. Nesse sentido, a epifania é a memória histórica da aura, é sua tradição, "mas diz igualmente, e literalmente, o sintoma: ela indica então o valor de epifania que pode ter o menor sintoma" (DIDI-HUBERMAN, 2010, p. 155).

O sintoma, como o que se repete, é o visual da imagem sobre o visível (no sentido do que pôde ser observado) em cada um dos encontros com os/as estudantes. As meninas são incessantemente silenciadas, muitas vezes até agredidas e humilhadas. De modo sistemático as brincadeiras e "tiradas" eram majoritariamente dirigidas a elas. Essa imagem sintoma também pode ser uma imagem intolerável.

\section{AS IMAGENS-SINTOMAS COMO A IMAGEM INTOLERÁVEL}

Nessa pesquisa, Rancière (2012, p. 83) se apresentou como um importante autor para pensarmos as relações entre os sujeitos e as imagens produzidas durante o processo vivenciado. A partir da ideia de imagens-sintoma apresentada anteriormente, é possível pensar que tais imagens também podem ser imagens intoleráveis, como nos propõe o autor:

O que torna uma imagem intolerável? A pergunta parece de início indagar apenas que características nos tornam incapazes de olhar uma imagem sem sentir dor ou indignação. Mas uma segunda pergunta logo se mostra implicada na primeira: será tolerável criar tais imagens ou propô-las à visão alheia?

Essa provocação parece bastante pertinente para as imagens produzidas durante a realização desta pesquisa. Rancière utiliza como ponto de partida a fotografia de uma modelo anoréxica publicada pelo fotógrafo Oliviero Toscani durante a semana de moda de Milão, em 2007. A imagem provocou, segundo o autor, dois pontos de vista opostos: um que dizia sobre a necessidade da imagem, outra que questionava se mostrá-la não seria novamente a proliferação das imagens espetaculares (DEBORD, 2003). Como se existissem imagens que mostram o que é real demais, intoleravelmente real demais para ser proposto como uma imagem. Esse questionamento é pertinente, no caso da imagem da semana de moda, não somente por uma dimensão de respeito à dignidade humana, mas também porque pode funcionar como culto ao próprio espetáculo, responsável pela possibilidade de existência de tal crueldade:

Persp. Online: hum \& sociais aplicada., Campos dos Goytacazes, 28 (10)98-113- 2020 
A imagem é declarada inapta para criticar a realidade por que faz parte do mesmo regime de visibilidade daquela realidade, que exibe alternadamente sua face de aparência brilhante e seu avesso de verdade sórdida que compõe um único e mesmo espetáculo. Esse deslocamento do intolerável na imagem para o intolerável da imagem esteve no cerne das tensões que afetaram a arte política (RANCIÈRE, 2012, p. 84).

Nesse caso, não haveria intolerável realidade que pudesse se opor ao mundo das aparências espetaculares. Existiria tão somente um único e mesmo fluxo de imagens: que garantem a busca excessiva pela magreza na moda, a qualquer custo. Mesmo modo de exibição que hoje seria responsável por constituir o intolerável:

Todas as imagens eram equivalentes, diziam de modo semelhante a mesma realidade intolerável: a de nossa vida separada de nós mesmos, transformada pela máquina do espetáculo em imagens mortas, diante de nós, contra nós. A partir daí parecia impossível conferir a qualquer imagem o poder de mostrar o intolerável e de nos levar a lutar contra ele (RANCIÈRE, 2012, p. 85-86).

Todas as afirmações e reflexões de Rancière nos levam a pensar que a grande busca desta investigação, a percepção e crítica do mundo sitiado por imagens através da própria produção e criação de imagens, não poderia acontecer.

Quando o autor questiona se as imagens querem realmente viver, ele nos responde: "As imagens não seriam nada - somente simulacros sem vida - e seriam tudo: a realidade da vida alienadas, a consistência do mundo das ligações sociais fundadas sobre a exploração" (RANCIÈRE 2012, p. 192). Nesse sentido, uma leitura atenta as ideias do autor nos levará a entender que, para ele, a única forma de criticar a passividade das imagens seria apostar no seu oposto: a própria ação com elas. Para contestar o mundo sitiado por imagens seria necessário, então, opor passividade - vida alienada - a "ação viva" da imagem.

Rancière (2012, p. 86) utiliza como ilustração o filme "Sociedade do Espetáculo", de Guy Debord, para falar de uma conclusão aparentemente paradoxal da denúncia do espetáculo na medida em que, se toda imagem mostra a vida invertida, passiva, bastaria "virá-la para desencadear o poder ativo que ela desviou":

\footnotetext{
Assim, é preciso imagens de ação, imagens da verdadeira realidade ou imagens imediatamente invertíveis em sua realidade verdadeira, para nos mostrar que o simples fato de ser espectador, o simples fato de olhar imagens é uma coisa ruim. A ação é apresentada como única resposta ao mal da imagem e à culpa do espectador. No entanto, o que se apresenta a esse espectador ainda são imagens. Esse aparente paradoxo tem sua razão: se não olhasse imagens, o espectador não seria culpado (RANCIÈRE, 2012, p. 87).
}

Essa culpa nos traria a denúncia da inversão da vida, dentro da qual seríamos apenas consumidores passivos de mercadorias que são imagens e de imagens que são mercadorias. Olhando para as imagens intoleráveis nunca agiremos, permaneceremos sendo espectadores de uma vida que virou imagem. No entanto, há, para o autor, a inversão da inversão, que acontece na ação. Essa ação se configura como um tipo de saber reservado daqueles que sabem porque ficaremos sempre a não saber, a não atuar. O conteúdo real dessa crítica nos deslocaria do "intolerável na imagem ao intolerável da imagem".

Para abordar tal temática, Rancière discute as quatro imagens da câmara de gás em Auschwitz, apresentadas na exposição "Memórias do campo de concentração". É fundamental aqui pensarmos a questão da testemunha trazida pelo autor. Essa perspectiva

Persp. Online: hum \& sociais aplicada., Campos dos Goytacazes, 28 (10)98-113- 2020 
pode dialogar com a posição das crianças da escola analisada. Nesse caso o argumento: "visa instaurar uma oposição radical entre dois tipos de representação, a imagem, visível e a narrativa pela palavra, dois tipos de atestação, a prova e o testemunho" (Rancière, 2012, p. 89). Como quando os desenhos das crianças nos mostram a situação da polícia e as diversas opressões que ela pratica são narradas, mas a questão jamais foi escolhida para ser registrada em forma de imagem e assim "comunicada" para fora dos nossos encontros durante a realização da Olhares (Im)Possíveis.

Voltaremos as imagens intoleráveis na próxima parte deste artigo. Mas antes, visto que trouxemos para o texto a ideia de Rancière sobre uma "inversão da vida", iremos apresentar o entendimento dele sobre a própria vida, a partir de uma relação estabelecida com o teatro. Ao falar do teatro do povo, o autor traz duas vezes a dimensão de um poder que é maior que o palco e também que próprio povo: "a vida, a Vida universal que atravessa e excede as vidas individuais" (RANCIÈRE, 2017, p. 127). Nesse contexto, e inclusive porque as práticas audiovisuais têm conexões diretas com o teatro (visto que o cinema surge nas fronteiras com teatro), "a Vida é o que faz do palco o lugar de uma nova dramaturgia, uma dramaturgia da coexistência” (RANCIÈRE, 2017, p. 127). O teatro não é apenas mais uma metáfora da ordem social, mas também uma metáfora do pensamento, expressão onde é possível e necessário abandonar as velhas convenções de personagens, linguagens e situações, para que a vida jorre. Sendo assim,

A vida é um meio em um novo sentido. Não o intervalo entre dois extremos, mas sim um tecido em que tudo se entrelaça infinitamente, tão bem que nunca se encontra o momento em que a causa começa a agir e que nunca se pode determinar o ponto onde seu efeito termina (RANCIÈRE, 2017, p. 130).

Podemos pensar, pois, que essas imagens intoleráveis podem sugerir a inversão da vida que o autor cita. Elas poderiam inverter a lógica da potência das imagens enquanto anulam a Vida em prol do espetáculo. Quando se movimentam, buscam um efeito específico, criado por causas também específicas. O autor fala de um Pictorial turn:

Pictorial turn, então, não designaria simplesmente uma redenção justa à imagem contra as acusações de inconsistência ou de grande consistência. O termo designaria uma virada histórica efetiva, uma mutação no modo de presença das imagens, não mais uma justiça dada pelo observador, mas uma vingança exercida pelas novas potências da imagem contra todos aquele que negaram seus poderes (RANCIÈRE, 2015, p. 194).

Foi essa a tentativa durante os 20 encontros realizados na escola Adhalmir Maia, os quais correspondem à primeira fase da metodologia, objeto desta pesquisa. De maio a dezembro de 2017, produzimos imagens com crianças - escutamos crianças através de imagens. Um trabalho que nos afetou mutuamente, diretamente, intensamente. Uma travessia repleta de esbarros em imagens-sintoma, intoleráveis. Às vezes nossas, as vezes deles/as. Uma delas, naquele momento, foi a que mais saltou os olhos: a violência com os corpos negros e periféricos, mesmo ainda que fossem crianças.

\section{Uma imagem intolerante nas imagens intoleráveis: a violência. Ou violência: a justiça como (im)possível e as micro-utopias da imagem intolerável}

Desde o primeiro encontro com as crianças já havíamos observado a questão da violência latente e presente nos seus corpos. Na medida em que as conversas seguiam, percebemos que as questões com a polícia seriam relatadas, testemunhadas e "denunciadas" cada vez mais. Ao criarem as cartografias dos sonhos, atividade realizada durante a

Persp. Online: hum \& sociais aplicada., Campos dos Goytacazes, 28 (10)98-113- 2020 
segunda parte da metodologia, o pedido de "menos violência" apareceu nos sonhos para o bairro.

O que chamamos de Olhares ( $\mathrm{Im}$ )Possíveis 2 aconteceu a partir do mês de agosto, quando retornamos à escola e criamos, de acordo com as necessidades das/os estudantes (e junto com eles/as), uma série de jogos/atividades dispositivos. $\mathrm{Na}$ ocasião, fizemos uma cartografia coletiva de sonhos. Apostar nos sonhos é acreditar que: "Pessoas são motivadas por ideias, traduzidos em sonhos, materializados nos projetos e ações ao longo da vida." (CARVALHO; SANTOS; OLIVEIRA; GALDINO, 2019, p. 37)

A violência quase sempre estava relacionada às abordagens policiais no barrio. Algo paradoxal: a polícia aparece como instituição que amedronta, mas é muito respeitada. Principalmente pelos meninos, que sonham em ser policiais e quase sempre se referiam ao Programa Educacional de Resistência às Drogas como uma referência de projeto que acontecia na escola.

Problematizar essa instituição é uma tarefa necessária, já que elegemos o Estado como responsável por coordenar essas dinâmicas. O Estado, por sua vez, cria a polícia como único aparato autorizado a usar da violência dentro de nossa sociedade. Nesse ponto, pensar a polícia também é tarefa complexa, visto que

se a polícia não existisse, cada um teria de recorrer à própria força para fazer valer seus direitos. [...] Viveríamos numa terra de ninguém, dominada pelos mais fortes. Por isso, o Estado - com a polícia e a Justiça - é tão importante para a vida coletiva. Sem ele não haveria democracia (SOARES, 2011, p. 33).

Luiz Eduardo Soares nos lembra também que não é sempre que a polícia e o Estado tratam todos como iguais, "há sempre um risco de que nem todos tenham acesso à Justiça e de que a polícia não trate todos os cidadãos com equidade, isto é, como iguais" (Soares, 2011, p. 31). A democracia, vai dizer o autor, "é negada na prática, e o Estado torna-se instrumento de desigualdade e injustiça. Sua força - policial e aparatos militares - convertese em meios de violência" (SOARES, 2011, p. 33-34).

Sabemos bem disso. Desde o primeiro encontro com as crianças, e especialmente nas conversas sobre os mapas afetivos, nos deparamos com o mais intolerável das imagens produzidas: o modo como esses meninos e meninas vivem rodeados pela violência. Tal fato é preocupante principalmente porque as "experiências traumáticas não ajudam a liberdade. Pelo contrário, a reduzem" (SOARES, 2011, p. 48). É importante salientar que todas as atitudes violentas que os meninos sofrem e reproduzem não dizem respeito diretamente à ação da polícia: a violência também está presente na relação com as professoras, com a família, com a criminalidade presente no bairro e também entre eles/as mesmos/as.

No primeiro dia de realização do filme-carta, por exemplo, nos chamou a atenção a situação da expulsão de um dos estudantes da atividade por não ter levado a autorização. É preciso considerar que na maioria das vezes algumas atitudes não acontecem com o propósito explícito. Ou seja: também há uma violência velada em forma de correção, de ensinamento.

Questionamos várias vezes o ditado popular quando percebia-se as atitudes violentas: será mesmo que "se não aprendemos pelo amor, será que aprendemos mesmo pela dor"? Parece possível mostrar "quanta violência pode se esconder sob a vontade e sob

Persp. Online: hum \& sociais aplicada., Campos dos Goytacazes, 28 (10)98-113- 2020 seer.perspectivasonline.com.br 
as práticas postas em marcha por essa vontade de cuidar, proteger, defender, dar segurança, educar, controlar e disciplinar" (SOARES, 2011, p.49).

Como pensar a questão da violência na infância? A punição, como sabemos, nem sempre é resolutiva, até mesmo por não se aplicar de modo igual para todas as crianças e adolescentes. Pensemos com Soares o sistema socioeducativo:

\begin{abstract}
O adolescente que cumpre medida nesses espaços lúgubres é pobre, mora na periferia ou na favela, comumente é negro. Quase não existem jovens de classe média, brancos, residentes nas áreas nobres das cidades, nesses internatos públicos. Isso não significa que os filhos das camadas médias e das elites não se envolvam em práticas ilegais - drogas, ações violentas contra outras pessoas, contra a propriedade alheia etc. Quer dizer, isso sim, que a Justiça - e antes dela a polícia -não é tão cega quanto se apregoa, isto é, não trata todos com equidade (SOARES, 2011, p. 53).
\end{abstract}

Enquanto sociedade, nos dizemos enquanto sujeitos vivendo em um Estado Democrático de Direito. Porém, é possível constatar que para algumas pessoas essa democracia não funciona em sua plenitude. Nossa democracia anda cada vez mais incerta e, cada vez mais, "na prática, uns são mais iguais que outros" (SOARES, 2011, p. 53).

Muitas vezes refletimos sobre as possibilidades que o trabalho com nas oficinas poderia trazer, que a prática poderia ter resultados efetivos. Na contramão, indagamos se não estávamos lidando com um grande medo a partir da realização desta pesquisa: sobre se o que estávamos conhecendo não era a possibilidade de, em um futuro não tão distante, nos depararmos com mais um jovem morto pela Polícia Militar.

Nunca é demais mencionar que a Polícia Militar brasileira mata. Mata nas grandes cidades, mas também mata no interior. Desde o dia 15 de setembro de 2017, pensamos todos os dias em modos de educar que permitam que as crianças que encontramos não sejam os próximos Igor Arcanjo Mendes, jovem negro, da periferia, morto pela Polícia Militar de Ouro Preto em 2017, ou como tantos outros das grandes cidades brasileiras. Não é novidade que casos como esse estampam as notícias de jornal de forma sistemática. $\mathrm{O}$ Genocídio da juventude negra é uma realidade em nosso país, infelizmente. A violência policial além de adultos, também faz as crianças de vítima. Nos últimos anos temos casos como o da menina Agatha Felix, de 08 anos, morta em 2019 no complexo do alemão. João Pedro, de 14 anos , em 2020. Só para citar os casos com as maiores repercussões.

A violência com o corpo negro "começa com a abordagem policial (que varia de acordo com a classe social, cor da pele, vestuário, idade e gênero do abordado)" (SOARES, 2011, p. 53), mas também persiste na escola, no comércio, e nas atividades cotidianas: o racismo em nosso país é institucional e estrutural.

Os/as estudantes que participaram da pesquisa, por exemplo, nos comentaram diversas vezes sobre serem submetidos a abordagens por seguranças de redes de supermercado e pela polícia durante as rondas que realizam no bairro. Tais situações foram registradas tantos nos mapas afetivos produzidos por ele/as, como nas conversações realizadas em torno dos caminhos cotidianos.

O mundo sem polícia e sem prisão: sonho ou ilusão? Essa é outra reflexão pertinente de Soares: assim como o autor (e aqui está o porquê da escrita do (im)possível com parêntesis), acreditamos que "utopias são esse norte que nos ajudam a definir um

Persp. Online: hum \& sociais aplicada., Campos dos Goytacazes, 28 (10)98-113- 2020 seer.perspectivasonline.com.br 
rumo" (SOARES, 2011, p. 124). No entanto, infelizmente, estamos bem distantes desses sonhos e fantasias sobre habitar o mundo socialmente sem conflitos:

\begin{abstract}
Antes da invenção da polícia, destinada a fazer com que os direitos e as liberdades sejam respeitados, e a constituição seja cumprida, o que havia eram grupos de linchadores ou tropas privadas, a serviço de senhores, aristocratas, nobres e latifundiários. Claro, alguém sempre pode dizer que isso não mudou tanto, porque as polícias em países como o nosso continuam defendendo os ricos e oprimindo os pobres. Tudo bem. Concordo. Infelizmente, tem sido assim mesmo, ao longo de nossa história (SOARES, 2011, p. 126).
\end{abstract}

Porém, não podemos aceitar que instituições sigam reproduzindo desigualdades sociais em um sistema de punições que ferem os direitos humanos. Soares propõe a passagem de uma "culpa individual para um responsabilidade coletiva". Quem entrega a escola de má qualidade para o/a estudante não é a professora, mas o Estado, este representado pelos governantes, os quais são eleitos por nós: eleitores. Desse modo,

é muito fácil apontar o dedo para o jovem vendedor de maconha e jogar sobre ele
a carga diabólica da violência e do crime. É simples culpá-lo pela insegurança.
Ele é nosso bode expiatório mais conveniente. A fonte do mal que nos livra de
toda a culpa e nos purifica. Ilusão. Ilusão perversa. Estamos todos implicados
nesse novelo. Estamos envolvidos até a raiz dos cabelos (SOARES, 2011, p.
143).

A vulnerabilidade é uma dimensão objetiva e econômica, mas também, nos lembra o autor, tem sua dimensão subjetiva que inclui:

processos emocionais, simbólicos, psicológicos, de aprendizagem e conhecimento, e também é claro, com fatores sociais e econômicos. Sem subestimar esses fatores materiais, a devastação da autoestima; a fome de reconhecimento; o papel do sexo e do desejo são extremamente importantes (SOARES, 2011, p. 153).

Nesse sentido, o que essas crianças em contexto de vulnerabilidade social parecem ter é também um pouco de suas infâncias roubada. Por isso, Levantamos a hipótese de que a vivência com a olhares (Im)Possíveis seria um resgate da infância desses meninos e meninas.

Uma leitura das vivências com as crianças, a partir de Clastres (2004), pode levantar a hipótese de que nossos encontros proporcionou também uma experiência de sociedade primitiva a partir do resgate dessa infância através da liberdade. Pois, "ao perder a liberdade, o homem perde sua humanidade. Ser humano é ser livre, o homem é um serpara-a-liberdade" (CLASTRES, 2004, p. 149). Para o autor, o estado primitivo de sociedade pode ser pensado como um estado de renúncia à servidão:

\footnotetext{
Não há passagem progressiva da liberdade à servidão: não há intermediários, não há a figura de um social equidistante da liberdade e da servidão, mas sim o brutal mau encontro que faz desabar o antes da liberdade no depois da submissão. Que quer dizer isso? É que toda relação de poder é opressiva, que toda sociedade dividida é habitada de um Mal absoluto pelo de fato de ser, como antinatureza, a negação da liberdade (CLASTRES, 2004, p. 150).
}

Podemos pensar, então, que o encontro com a linguagem audiovisual seja esse bom encontro. Um encontro que nos lembra que a divisão não é uma estrutura ontológica da sociedade. Talvez por isso o resgate seja tarefa importante dessa prática, voltar ao antes (da infância, do mafuá, da desordem, do primitivo) é estar em conformidade com a natureza do

Persp. Online: hum \& sociais aplicada., Campos dos Goytacazes, 28 (10)98-113- 2020 seer.perspectivasonline.com.br 
homem em uma "sociedade sem opressão e sem submissão" (CLASTRES, 2004, p. 150). Acreditamos que a vivência audiovisual proporciona uma experiência selvagem que resgata os vagalumes:

Selvagens anteriores à civilização, povos anteriores a escrita, sociedades anteriores à história: essas sociedades são, certamente, bem nomeadas de primitivas, sociedades primeiras por se manifestarem na ignorância da divisão, primeiras por existirem antes do fatal mau encontro. Objetivo privilegiado, quando não excluído da etnologia: as sociedades sem estado (CLASTRES, 2004, p. 150-151).

O que garantimos com o projeto foi a possibilidade de uma espécie de "implosão do Estado", ainda que por poucos momentos. Ou pelo menos um espaço de afastamento as lógicas necropolíticas (Mbembe, 2018) impostas por algumas instituições. Criamos espaços onde as forças repressoras do Estado não agia: por isso, além de vagalumes, fomos primitivos através de uma prática/experiência com a câmera e para além dela. Vale dizer que o desenho da metodologia não diz sobre como responder perguntas, mas procura diagnosticar como, quais e por onde nossas perguntas e questões deveriam passar.

As oficinas foram um espaço que permite que todos os envolvidos dialogassem, e não somente discursarem. A intenção do trabalho sempre foi criar um espaço e uma vivência onde o poder não seja estático, mas que circule entre todos/as, mesmo que por um único momento. A Olhares (Im)Possíveis é uma micro-utopia do (im)possível sempre em parênteses. Através da linguagem audiovisual, essas crianças puderam ser produtoras de espaços. Essa ideia nos obriga a considerar

\begin{abstract}
o sujeito da ação: o Estado, como aquele da dominação política; o capital com suas estratégias objetivando sua reprodução continuada (e aqui nos referimos às frações do capital: o industrial, o comercial e o financeiro e suas articulações com os demais setores da economia, como o mercado imobiliário); os sujeitos sociais que, em suas necessidades e seus desejos vinculados à realização da vida urbana, tem o espaço como condição, meio e produto de sua ação. Esses níveis correspondem àqueles da prática sócio-espacial real (objetiva e subjetivamente) que ganha sentido como produtora dos lugares, encerrando em sua natureza um conteúdo social dado pelas relações sociais que se realizam num espaco-tempo determinado, como um processo de produção, apropriação, reprodução da vida, da realidade e do espaço em seus descompassos, portanto, fundamentalmente, em suas contradições (CARLOS, 2011, p. 64).
\end{abstract}

A olhares possibilitou uma análise extra-fílmica do próprio cinema (vídeo): é uma (des)pedagogia do cinema extra fílmico. Ao cartografar a cidade através de imagens produzidas no cotidiano o que se garante é a possibilidade de criação de cartografias-outras. Esses procedimentos de intensa abertura operam garantindo outras possibilidades para os espaços, logo, para os sujeitos. Essas cartografias de pesquisa engendram imagens (im)possíveis, garantindo novas possibilidades para as crianças envolvidas.

\title{
4. CONCLUSÕES
}

\section{AS IMAGENS (IM)POSSÍVEIS SURGEM NOS PROCESSOS}

Por focar no processo e seus possíveis laços, o ponto principal de sucesso da prática é o espaço de partilha do sensível (Rancière, 2012) que se cria com as crianças envolvidas. Percebemos o engajamento delas com as atividades, inclusive no contra turno.

Persp. Online: hum \& sociais aplicada., Campos dos Goytacazes, 28 (10)98-113- 2020 seer.perspectivasonline.com.br 
Além disso, destacamos outros pontos fundamentais para os resultados alcançados: a) a escuta dos estudantes em um terreno (educação) onde muitas vezes não são escutados seus desejos; b) a possibilidade de resgate da infância perdida em contextos de vulnerabilidade social através de atividades lúdicas; c) a prática fez emergir questões e testemunhos das histórias de vida das crianças sem que isso fosse feito de maneira indireta é a partir disso que se torna possível identificar as questões e atuar; d) a criação do sentimento de pertencimento tanto com o bairro como com a escola. $\mathrm{O}$ mesmo sentimento aparece em relação ao grupo; e) a possibilidade da ampliação do olhar dos envolvidos, o que pode garantir outras chances de escolha para eles/as, causando de certa forma um afastamento das realidades cruéis em que estão inseridos.

Por último, é importante dizer que esse artigo reflete sobre a primeira experiência com essa metodologia. Desde então, já realizamos trabalhos com mais de 20 grupos em 5 cidades mineiras. Os estudantes que participaram das primeiras atividades já conseguem se deslocar do lugar traumático inicial e expandem nossas atividades com o cinema para práticas de cuidado. Por exemplo, cuidar da horta escolar e modificar esse espaço (atividade realizada em 2019).

Alguns deles já frequentaram um importante festival de cinema documentário para apresentar um dos filmes que produzimos em 2018. Ao serem posicionados como cineastas, os meninos e meninas aceitam essa posição e isso também expande o modo como se relacionam com o mundo, através da incorporação da linguagem audiovisual em seus cotidianos e práticas.

\section{REFERENCIAS}

ARAUJO, Arthur Medrado Soares. Olhares (im)possíveis : desenvolvimento e aplicação de metodologia para a escuta do indizível com crianças da periferia de Ouro Preto. 2018. 144 f. Dissertação (Mestrado em Educação) - Instituto de Ciências Humanas e Sociais, Universidade Federal de Ouro Preto. Mariana, 2018.

CARLOS, A. F. A. Da "organização" à "produção" do espaço no movimento do pensamento geográfico brasileiro. In: __ et al (Org.). A produção do espaço urbano. São Paulo: Editora Contexto, 2011. p. 53-72

CARVAlHO, L. A.; SANTOS, S. F.; OLIVEIRA, L. F. P.; GALDINO, M. E. R. Tecnologias digitais de informação e comunicação (TDIC's) e a sala de aula. Perspectivas Online: Humanas \& Sociais Aplicadas, v. 9, n. 26 , p. 32-51, 2019.

CLASTRES, P. Arqueologia da violência: pesquisas de antropologia política. São Paulo: Cosac \& Naify, 2004.

DIDI-HUBERMAN, G. Ante el Tiempo. Tradução para o espanhol: Oscar Antonio Oviedo Funes. Buenos Aires: Adriana Hidalgo Editora, 2005.

DIDI-HUBERMAN, G. O que vemos, o que nos olha. São Paulo: Editora 34, 2010.

DIDI-HUBERMAN, G. Diante da imagem. São Paulo: Editora 34, 2013.

DIDI-HUBERMAN, G. Sobrevivência dos vaga-lumes. Belo Horizonte: Editora UFMG, 2011.

Persp. Online: hum \& sociais aplicada., Campos dos Goytacazes, 28 (10)98-113- 2020 seer.perspectivasonline.com.br 
GINZBURG, C. Mitos, emblemas, sinais: morfologia e história. São Paulo: Companhia das Letras, 1989.

MBEMBE, A. Necropolítica. São Paulo, sp: N-1 edições, 2018.

MIGLIORIN, C. Inevitavelmente Cinema: Educação, política e mafuá. Rio de Janeiro: Beco do Azougue, 2015.

MIGLIORIN, C. [et al] Inventar com a diferença: cinema e direitos humanos. Niterói: Editora UFF, 2014.

MEDRADO, A.; DINIZ, M. Aposta Contemporânea de pesquisa-intervenção: impasses entre objetividade e subjetividade nas Ciências Humanas. Missões: Revista de Ciências Humanas e Sociais, v. 6, n. 1, p. 102-120, 3 jun. 2020.

PASSOS, E.; KASTRUP, V.; ESCÓSSIA, L. (Orgs.). Pistas do método da cartografia: pesquisa-intervenção e produção de subjetividade. Porto Alegre: Sulina, 2009.

RANCIÈRE, J. O inconsciente estético. São Paulo: EXO/34, 2009.

RANCIÈRE, J. O espectador emancipado. São Paulo: Martins Fontes, 2012.

RANCIÈRE, J. As imagens querem realmente viver? In: ALLOA, Emmanuel (Org.). Pensar a imagem. São Paulo: Editora Autêntica, 2015. p. 191-204.

RANCIÈRE, J. Os nomes da história. São Paulo: Editora Unesp, 2017.

SILVEIRA, P. C. A. Etnotopografia aplicada em praças: algumas ferramentas para ler a cidade em arquitetura e urbanismo. Perspectivas Online:Humanas \& Sociais Aplicadas, v. 10, n. 27, p. 1 -21, 2020

SOARES, L. E. Justiça: pensando alto sobre violência, crime e castigo. Rio de Janeiro: Nova Fronteira, 2011. 